\title{
Processos de Criação em Anne Sauvagnargues
}

\author{
Processes of Creation in Anne \\ Sauvagnargues \\ Procesos de Creación en Anne \\ Sauvagnargues
}

\author{
Édio Raniere da Silva ${ }^{1}$ \\ Andressa Silveira da Silva ${ }^{2}$
}

\footnotetext{
1 Pós-Doutorado em Filosofia pela Université Paris-Nanterre. Doutor em Psicologia Social e Institucional pela Universidade Federal do Rio Grande do Sul. Professor Adjunto do Curso de Psicologia da Universidade Federal de Pelotas - UFPel, onde coordena o Laboratório de Arte e Psicologia Social: LAPSO. Vice-presidente da Associação Brasileira de Psicologia Social - ABRAPSO. Suas principais pesquisas concentram-se em dois eixos temáticos: 1) Medidas Socioeducativas; 2) Ressonâncias entre Arte e Psicologia Social. Interessa-se pelas obras de Gilles Deleuze, Friedrich Nietzsche e Anne Sauvagnargues.

Currículo Lattes: http://lattes.cnpq.br/4498767706666013 ID Orcid: https://orcid. org/0000-0002-0216-678X, Email: edioraniere@gmail.com.

${ }^{2}$ Graduada em Artes Visuais (bacharelado) pela Universidade Federal do Rio Grande Furg. Graduanda em Psicologia pela Universidade Federal de Pelotas - UFPel. Integra a equipe do laboratório de arte e psicologia social - LAPSO, e do núcleo abrapso sulsul. Email: andressa.silveira@hotmail.com, Currículo Lattes: http://lattes.cnpq. br/1410927809634758 ID Orcid:

https://orcid.org/0000-0001-8568-2159
} 


\title{
Revista Apotheke
}

\section{Resumo}

O presente artigo busca problematizar os processos de criação a partir da obra de Anne Sauvagnargues. Para isso apresenta uma introdução sobre a concepção elaborada por esta artista e filósofa, tendo como objeto de análise três de suas pinturas: "Station Saint Michel", "Viva Italia!" e "Arrêt à Marseille". A partir dessa exposição inicial desenvolve-se, então, uma aproximação com o conceito de bloqueio - visto que para a autora é o bloqueio quem cria - e com a noção de subtração - visto que para Sauvagnargues a criação é sempre subtrativa. A hipótese defendida pelo ensaio é de que haja uma teoria da criação em Anne Sauvagnargues que ao mesmo tempo se relaciona com a ideia de bloqueio - a qual seria distinta de uma determinada compreensão do conceito de resistência em Gilles Deleuze: criar é resistir - e com a subtração enquanto invalidação de uma lei naturalizada. Naturalização que, por sua vez, impede a percepção de que a defesa de sistemas coerentes são sempre imposições de uma leitura em específico. Nesse sentido, a aposta do trabalho é de que a obra de Anne Sauvagnargues, ainda pouco traduzida no Brasil, tenha contribuições importantes para cartografias cuja intenção passe pelo mapeamento de relações que envolvem os processos de criação e os processos de subjetivação.

\section{Palavras-chave}

processos de criação; Anne Sauvagnargues; Gilles Deleuze; bloqueio; subtração.

\begin{abstract}
This paper consists in problematize the processes of creation based on the work of Anne Sauvagnargues. For that, it shows an introduction to the conception elaborated by this artist and philosopher. The object of analysis are three of her paintings: "Station Saint Michel", "Viva Italia!" and "Arrêt à Marseille". The initial exposure increase, an approximation with the concept of blockage develops - for the author the blockage is who creates - and with the notion of subtraction - since for Sauvagnargues, creation is always subtractive. The hypothesis defended by the trial is that there is a creation theory in Anne Sauvagnargues at the same time is related to the idea of blockage which could be distinct from a certain understanding about the concept of resistance in Gilles Deleuze: to create is to resist - and with subtraction while invalidating a naturalized law. Naturalization, in turn, prevents the perception that the defense of coherent systems are always impositions of a specific reading. In this direction, the paper's bet is that Anne Sauvagnargues' work, seldom translated in Brazil, have important contributions to cartography whose intention is to map relationships that involve the processes of creation and processes of subjectification.
\end{abstract}

\section{Keywords}

processes of creation; Anne Sauvagnargues; Gilles Deleuze; blockage; subtraction.

\section{Resumen}

Este artículo busca problematizar los procesos de creación basados en el trabajo de Anne Sauvagnargues. Para eso, presenta una introducción a la concepción elaborada por esta artista y filósofa, que tiene como objeto de análisis tres de sus pinturas: "Station Saint Michel", "Viva Italia!" y "Arrêt à Marseille". A partir de esta exposición inicial, entonces, se desarrolla una aproximación con el concepto de bloqueo, ya que para el autor es el bloqueo quien crea, y con la noción de substracción, visto que para Sauvagnargues, la creación siempre es substractiva. La hipótesis defendida por el ensayo es que hay una teoría de la creación en Anne Sauvagnargues que al mismo tiempo está relacionada con la idea de bloqueo, lo que sería distinto de una cierta comprensión del concepto de resistencia en Gilles Deleuze: crear es resistir, y con substracción mientras invalida una ley naturalizada. La naturalización, que a su vez, impide la percepción de que la defensa de sistemas coherentes son siempre imposiciones de una lectura específica. En este sentido, la apuesta del trabajo es que el trabajo de Anne Sauvagnargues, aún poco traducido en Brasil, tiene importantes contribuciones a la cartografía cuya intención es mapear las relaciones que involucran los procesos de creación y los procesos de subjetivación.

\section{Palabras-clave}

procesos de creación; Anne Sauvagnargues; Gilles Deleuze; bloqueo; substracción.

ISSN: 2447-1267 


\section{Notas Introdutórias}

O debate em torno dos processos de criação sofreu (e ainda sofre) atravessamentos de diversos pressupostos culturais, sociais e filosóficos ao longo da história da arte. Entre eles, uma das análises mais pertinentes se deu em torno da construção e transformação da identidade artística. Durante toda a evolução da arte o processo de criação esteve sempre associado a uma construção histórica de um sujeito criador, seja ele considerado feiticeiro, artesão, gênio, louco, pesquisador...

Não é raro encontrar leituras sobre a arte rupestre agenciadas à crença de magias e poderes oriundos das forças da natureza, capaz de tornar real aquilo que estava sendo representado através da pintura. Nestas leituras o "artista" costuma ser associado a uma espécie de feiticeiro. (SOUZA, 2016). Em algumas dessas situações a arte chega a ser concebida como algo inerente ao sagrado, produção divina, e o artista não raramente chega a ser considerado um meio para a manifestação do divino, um vidente que teria como função expressar a mensagem enviada a ele. (NEUMANN, 1992)

Em outros contextos o artista aparece se retirando deste jogo de adoração e inspiração divina à medida que se aproxima do desenvolvimento de um culto à personalidade. $O$ Renascimento costuma ser tomado como ponto de clivagem nesse sentido. A partir dele, o artista passaria a ser valorizado por seu talento individual. (NEUMANN, 1992). Ou seja, o artista seria visto, desde então, como uma espécie de herói cultural, um grande criador/mestre cujo trabalho, constituído a partir do seu talento artístico, estaria relacionado com algo de próprio, original, exclusivo de sua individualidade.

Para além destes exemplos e destas influências históricas e filosóficas, a evolução da arte assume o papel de inserir, sucessivamente, novos elementos na trajetória que envolve os processos de criação. Nessa perspectiva, destacamos o trabalho da artista e filósofa Anne Sauvagnargues, que nos apresenta a hipótese de uma teoria da criação que transcende a noção de um sujeito criador.

Pesquisadora da história da arte e da estética, Anne Sauvagnargues dedicase, atualmente, ao desenvolvimento de uma Ecologia das Imagens, onde conceitos da filosofia da diferença dialogam intensivamente com sua poética em pintura, abrindo espaço para oferecer novas abordagens ao conceito de imagem. A filósofa é considerada uma das maiores especialistas no pensamento de Gilles Deleuze, onde vem explorando o fio que atravessa toda obra deste autor em sua aproximação com a arte.

Acreditamos, portanto, que as obras e os conceitos elaborados por Sauvagnargues possam trazer contribuições importantes para se pensar o fazer artístico na esfera da arte contemporânea. Nesse sentido, o presente artigo busca apresentar uma introdução a concepção elaborada por Sauvagnargues sobre os processos de criação.

Partindo do pensamento e das obras de Sauvagnargues, questionamos: $\bigcirc$ que seria um ato de criação? Como ele se processa? Como acontece? De que forma ele 
depende de um sujeito criador? Em que medida o ato de criação subjetiva o sujeito que o executa? E o mais importante: haveria mesmo um ato de criação agenciado pela subjetividade ou todos os processos relacionados à subjetivação, bem como à criação, seriam disparados por uma espécie de passividade constituinte?

Para tentar responder estas perguntas, iremos começar apresentando três pinturas ${ }^{1}$ expostas por Sauvagnargues - "Station Saint Michel", "Viva Italia!" e "Arrêt à Marseille" - a partir das quais tentaremos ilustrar como se dá seu processo de criação e sua relação com o espaço de criação. Na sequência trabalharemos com o conceito de bloqueio e com a noção de subtração na tentativa de apresentar algumas pistas sobre a teoria da criação em Sauvagnargues. Por fim, tentaremos apresentar uma introdução ao conceito de bloqueio, bem como à noção de subtração - conforme elaborados pela filósofa - agenciando-os as pinturas da artista. De modo geral, acreditamos estar diante de uma obra que nos convida a ocupar espaços para além do espectador - seja ele emancipado ou não - nos provocando a pensar e a criar modos de habitar o mundo.

\section{Processos de Criação}

Em suas pinturas Anne Sauvagnargues busca cartografar o movimento das cidades. Marseille, Paris, Milão, são tantas. Sua pintura agencia-se a um deslocamento, quase sempre realizado em transportes coletivos. Nesse trânsito algo acontece entre a paleta de cores, a velocidade da circulação e as imagens percebidas no desaparecimento do entorno. Nesses transportes coletivos transmutados em ateliers de pintura, a técnica aparece relacionada ao limite físico de uma poltrona onde a artista busca se acomodar sem atrapalhar os demais passageiros. Neste viés, a cartela de cores é selecionada ao acaso, através de poucos lápis/canetas os quais consegue suportar em sua mão. Uma vez selecionada sua paleta, Anne se mantém atenta aos detalhes que estão relacionados com estas cores. Os traços feitos sobre a folha libertam-se dos registros semânticos de um significado representativo. Não apenas sua pintura busca cartografar o movimento da cidade, como a própria cidade cartografa sua pintura, na medida em que a paisagem captada por ela em um curto espaço de tempo se torna obsoleta, dando espaço para novas configurações. A obra

\footnotetext{
1 Ao longo do texto iremos nos referir a poética visual de Anne Sauvagnargues como pintura. Esta opção está relacionada com três fatores: a) $\mathrm{O}$ modo como a artista se refere ao seu trabalho. Ou seja, é a própria Anne Sauvagnargues que apresenta sua obra como pintura, ver 'Somos Nada Mais que Imagens' (SAUVAGNARGUES, 2020). b) A fundamentação teórica do ensaio vem da filosofia da diferença. Como Deleuze e Guattari são críticos bastante conhecidos do modelo representacional não nos parece coerente sustentar aqui hierarquias entre regimes de visibilidades e de dizibilidades.c) Estamos de acordo com CATTANI (2004) e COSTA (2020), quando sustentam que aquilo "que constitui alguém como pintor, não é o emprego dos materiais e técnicas próprios à pintura, nem o reconhecimento social historicamente datado. A pintura coloca questões próprias, internas a ela mesma; o embate com essas questões, o seu afrontamento no próprio campo pictural, é que faz de alguém um pintor" (CATTANI, 2004, p.87).
} 
visual de Anne Sauvagnargues parece lembrar o tempo todo que o desejo não é algo interno ao sujeito ${ }^{2}$. São pinturas agenciadas a paisagens que passam rapidamente e não ao desejo individual da artista. Tais composições se misturam com o acaso, com o deslocamento, com as pausas e as velocidades do trem. "Station Saint Michel" (fig.1), "Viva Italia!" (fig.2), "Arrêt à Marseille" (fig.3), linhas, cores e movimento. São formas que são vistas em curso, estão a todo tempo aparecendo e desaparecendo. A pintura de Anne emerge dos encontros inesperados entre sua técnica, o transporte e a cidade.

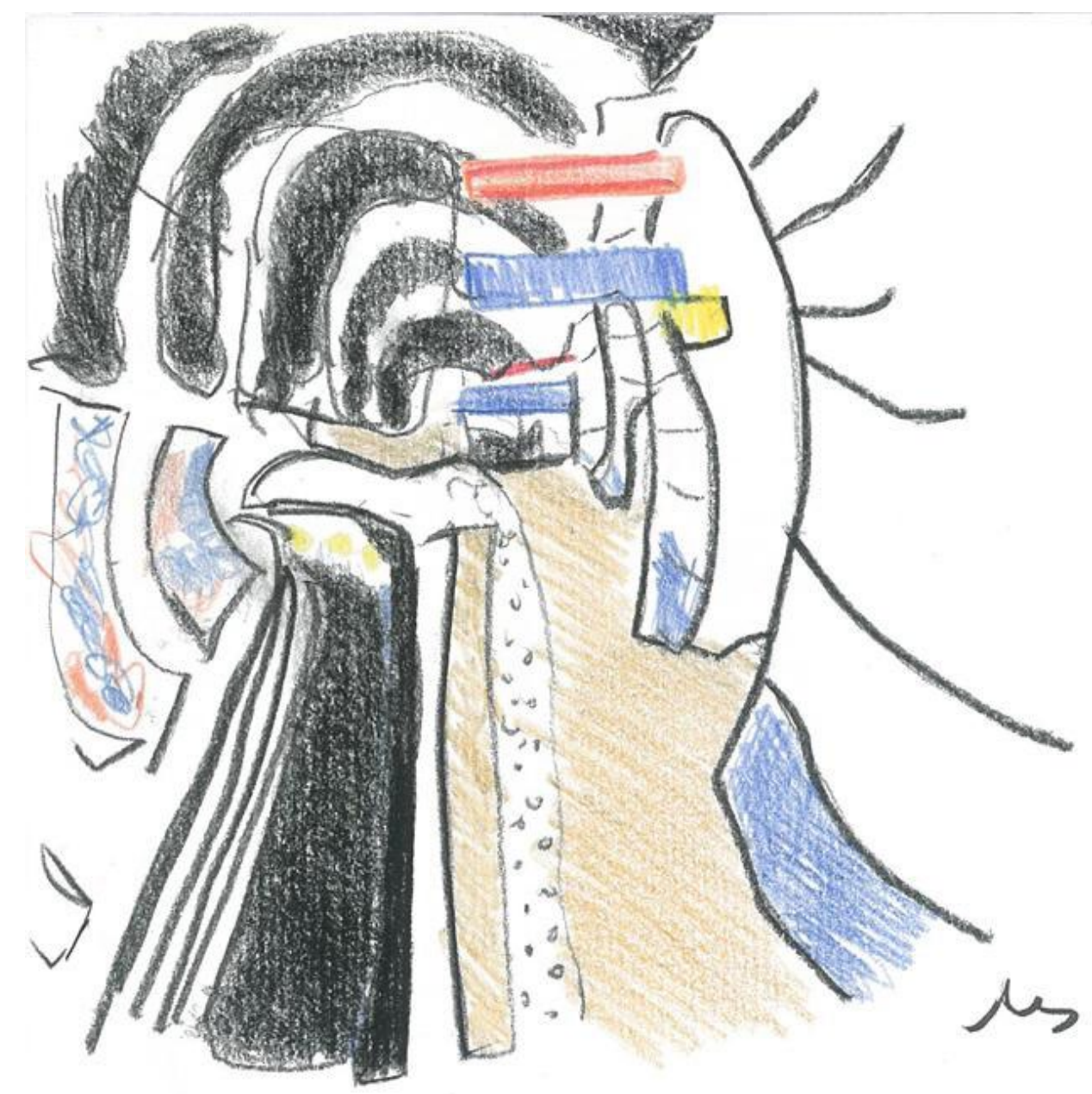

Fig.1, Anne Sauvagnargues, Station Saint Michel, 2001, Crayons couleur sur papier, 15×21cm. Fonte:https://richterbuxtorf.ch/particules-urbaines-dessins/

\footnotetext{
2 Não é o desejo que está no sujeito, mas a máquina é que está no desejo - e o sujeito residual está do outro lado, ao lado da máquina, sobre todo contorno, parasita das máquinas, acessório do desejo vértebro-maquinado. (DELEUZE; GUATTARI, 2010, p.377)
} 


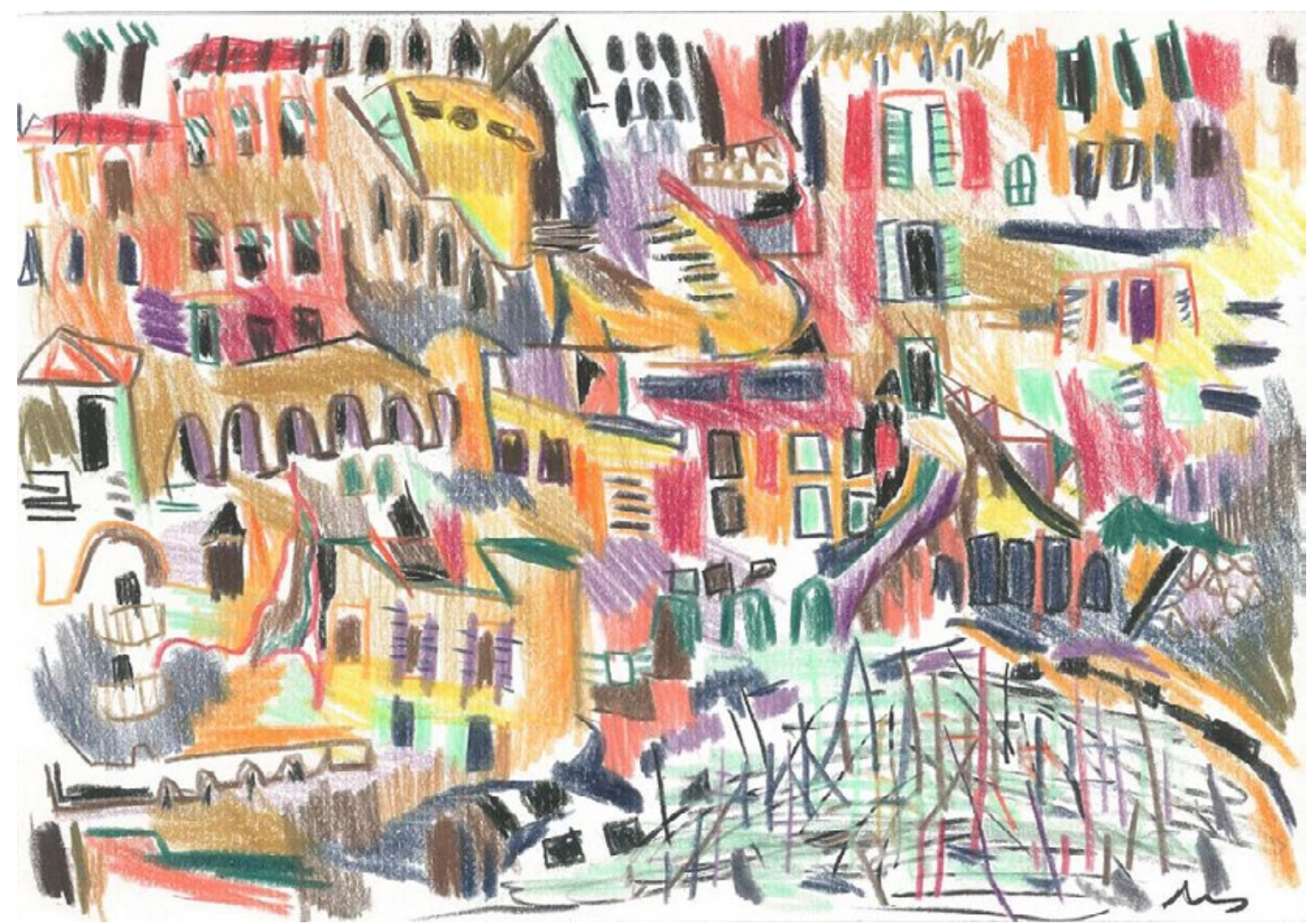

Fig. 2, Anne Sauvagnargues, Viva Italia!, 2001, Crayons couleur sur papier, 15x21cm. Fonte:https:// richterbuxtorf.ch/particules-urbaines-dessins/

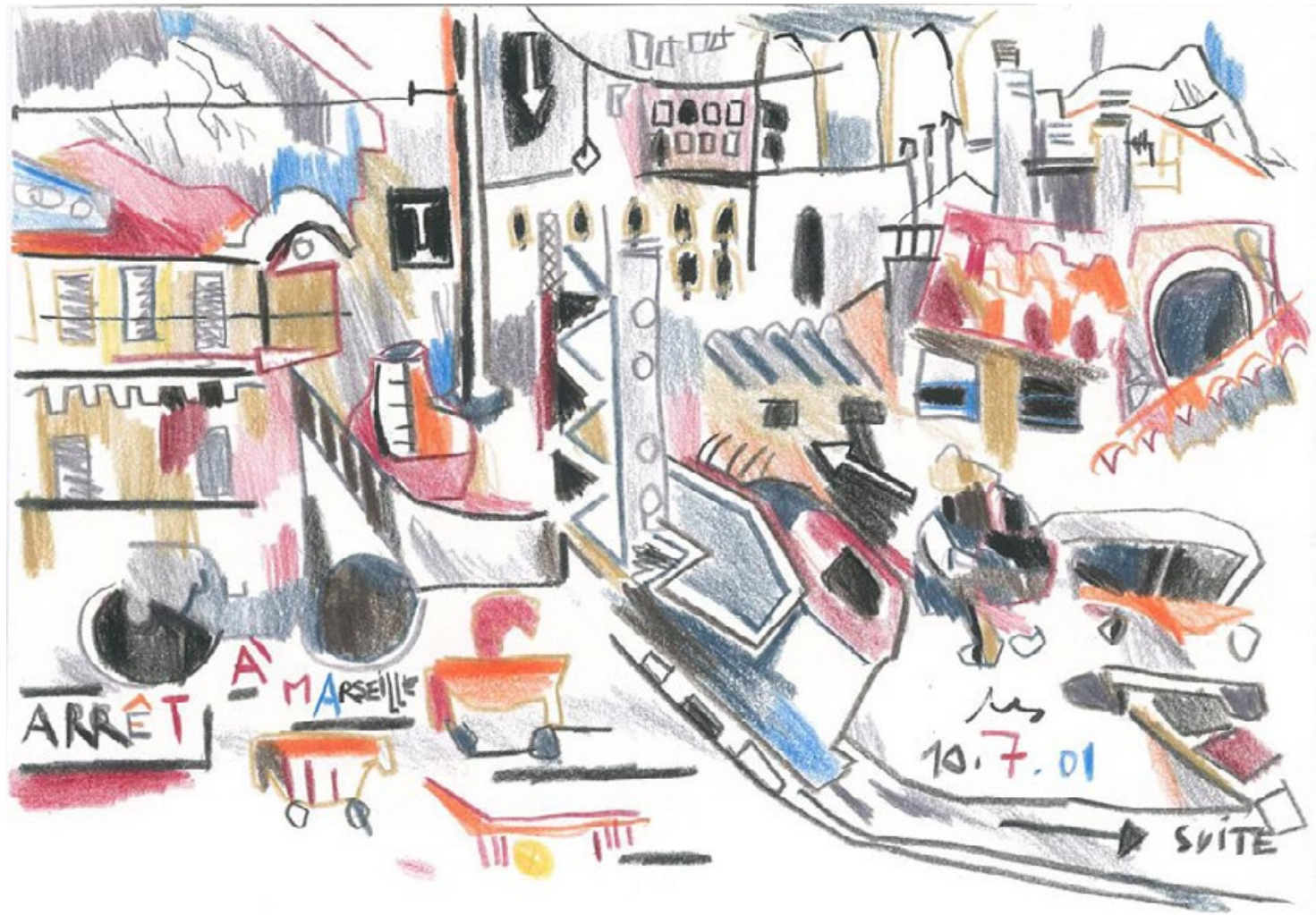

Fig.3, Anne Sauvagnargues, Arrêt à Marseille, 2001, Crayons couleur sur papier, 15×21cm. Fonte:https://richterbuxtorf.ch/particules-urbaines-dessins/ 


\section{Bloqueio e Subtração}

Em 'Deleuze et l'art' (2005), bem como em 'Deleuze: Del animal al arte' (2006) Anne Sauvagnargues associa os processos de criação ao conceito de bloqueio e a noção de subtração. Na tentativa de compreender a relação proposta por Sauvagnargues entre criação e subtração/bloqueio, vamos partir de uma conhecida fórmula deleuzeana:

Criar é Resistir ${ }^{3}$.

Numa entrevista recentemente publicada - somos nada mais que imagens Anne Sauvagnargues combate determinada leitura dessa fórmula. Pois, para ela a ideia de resistência pode nos empurrar a uma dialética e mesmo a um pensamento conservador. Onde para criar seria preciso, sempre, se opor a algo. Na entrevista em questão Sauvagnargues busca, então, distinguir o modo como Deleuze e Foucault lidam com a noção de resistência. Enquanto Deleuze prefere as linhas de fuga, Foucault buscaria por uma espécie de estatuto da resistência. Anne cita então o que seria na tradução brasileira o livro 3 de 'Mil Platôs' (1996) como exemplo da crítica feita por Deleuze a posição de Foucault diante à noção de resistência. O mesmo podemos encontrar em A Ilha Deserta (2006) e no ensaio Prazer e Desejo:

Para mim, não há o problema de um estatuto dos fenômenos de resistência: já que as linhas de fuga são determinações primeiras, já que o desejo agência o campo social, são, sobretudo os dispositivos de poder que se acham produzidos por esses agenciamentos, ao mesmo tempo em que esmagam ou os colmatam. Compartilho do horror de Michel por aqueles que se dizem marginais: acho cada vez menos suportável o romantismo da loucura, da delinqüência, da perversão, da droga. Mas para mim, não são criadas pelos marginais as linhas de fuga, isto é, os agenciamentos de desejo. Ao contrário, elas são linhas objetivas que atravessam uma sociedade, na qual os marginais instalam-se aqui ou ali para fazer um círculo, um circuito, uma recodificação. Não tenho, pois, a necessidade de um estatuto dos fenômenos de resistência, uma vez que o primeiro dado de uma sociedade é que nela tudo foge, tudo se desterritorializa. (DELEUZE, 2016, p.133-134)

Nesse sentido é que Sauvagnargues prefere o bloqueio à resistência. É como se a noção de resistência comportasse ainda um velho antropocentrismo humanista. O conceito pode e costuma ser utilizado como se todo processo dependesse de um sujeito que resiste. Como se a resistência partisse de alguém que resiste. O marginal que se opõe ao poder. Mas, se não estamos operando com a noção de sujeito ativo, como fazem as fenomenologias e os humanismos, então não faz sentido pensar a ação de oposição ao poder partindo de um sujeito.

(...) definir a arte como resistência é fazer dela uma resposta a algo que já existe. É resistir a alguma coisa. E por isso é reacionário, mas no sentido próprio do termo, quer dizer, é uma reação a uma situação. Se fosse uma resistência estaríamos, ainda, presos na relação entre indivíduo e sociedade.

\footnotetext{
${ }^{3}$ Abecedário de Gilles Deleuze, em R de resistência (1998); O que é a Filosofia (2010).
} 
Não é uma resistência ao social - indivíduo-social. É sim uma linha de fuga que se apoia em impossibilidades, mas para constituir algo que não é resistência, e sim abertura. Ou seja, a linha de fuga se apoia sobre os bloqueios da sociedade. (SAUVAGNARGUES, 2020, p.12)

Importante considerar que não são os sujeitos geniais os criadores das linhas de fuga; pelo contrário, as linhas de fuga são linhas objetivas que atravessam uma sociedade, na qual nos instalamos aqui e acolá para fazer um círculo, um circuito, uma recodificação. Artistas considerados geniais pela história da arte, bem como os marginalizados, instalam-se nelas da mesma forma. Na tentativa de evitar confusões como essas Anne Sauvagnargues apresenta o conceito de bloqueio para pensar a criação. A fórmula sugerida em 'Deleuze et l'art' (2005) é a seguinte: as condições de criação se efetuam a partir de uma forma de bloqueio, ou seja: o bloqueio é quem cria.

A ação isolada de um sujeito especial, distinto dos demais, o ato de criação do artista genial, o gesto metafísico do Deus criador, muitas vezes presente em algumas fenomenologias e humanismos como ação psicológica individual, perde importância aqui. Se em certa leitura o conceito de resistência concede abrigo a este sujeito extraordinário, o mesmo não é possível diante o bloqueio. Ou seja, no modo como Anne Sauvagnargues pensa os processos de criação as ações psicológicas individuais de um artista festejado pela história da arte possuem relevância menor que as forças de composição que o atravessam. O foco deixa de ser o gesto isolado, tido como criador nos humanismos e passar a ser o pré-individual, o impessoal.

Em alguns aspectos, Deleuze permanece preso ao antigo enquadramento, mas ao mesmo tempo permite que nos libertemos do velho paradigma da arte, atualmente obsoleto e perturbador onde o artista - sempre masculino, obviamente - "grande artista de exceção", o grande artista que é diferente das pessoas comuns porque é genial, e sua alma é justamente o que the permite sentir melhor a realidade do que todos os demais. (...) Então, por um lado, Deleuze conserva um pouco a ideia do artista genial, mas de outro, ele nos permite pensar os indivíduos e os sujeitos humanos como algo diferente de pequenas almas separadas umas das outras. E é por isso que, um dos grandes interesses do meu trabalho, tanto em pintura, como em filosofia e escrita, se entrega ao impessoal, ao pré-individual. Ou seja, não é que eu pense que o "eu" não exista: eu existo! Mas eu existo como um nó complexo de relações exteriores. E assim, quando penso, não sou eu sozinha pensando - e eu agradeço! (risos) -, é a relação entre mim, o transporte, a cidade e o acontecimento singular desse trajeto, com seus encontros que permitem alinhar, organizar, agenciar signos. (SAUVAGNARGUES, 2020, p.7-8)

Agenciamentos que ocorreriam de modo completamente diferente se o processo de criação desta pintora acontecesse em um atelier tradicional. $\bigcirc$ conceito de bloqueio nos parece importante, pois, insere elementos completamente novos aos debates sobre os processos de criação. Ao lado desse conceito a filósofa em questão trabalha, como anunciamos anteriormente, com a noção de subtração. Mas subtração de quê? Vamos tentar uma aproximação ao conceito partindo do problema da percepção. 
As psicologias tradicionais - pautadas na noção de sujeito - compreendem a percepção como adição. Para essas psicologias haveria uma espécie de grão interior em nós que vai se desenvolvendo conforme adicionamos a ele novos elementos. Tal qual um bichinho que vai engordando enquanto ganha comida, nossa subjetividade, para tais psicologias, se formaria à medida que nos relacionamos com o mundo e o interiorizamos. Segundo esse modo tradicional - seja via psicanálise, fenomenologia ou behaviorismo - nós nos tornamos isso que somos por adição, adicionando mundos a nossa alma individual. Mas, para realizar essa operação, tais psicologias lançam mão de uma metafísica: criam um ponto de origem da percepção no espaço interior do sujeito que percebe. A percepção seria, portanto, uma ação cuja origem estaria num sujeito ativo. É o sujeito que percebe e ao perceber adiciona tais percepções à sua subjetividade. A partir de um intenso diálogo entre Deleuze e Bergson a pensadora francesa nos propõe algo bem diferente: (...) "há percepção quando há subtração. Portanto, a percepção afasta da realidade tudo aquilo que não me interessa e que não entra em consonância comigo" (SAUVAGNARGUES, 2020, p.09)

À medida que a subtração abre condições de possibilidade para a percepção, o sujeito, visto pelas psicologias tradicionais como ativo, fonte originária da percepção, vai se deslocando rumo a uma espécie de passividade constituinte. Este modo de compreender a percepção não necessita mais de uma subjetividade completa, teológica, herdeira da alma metafísica, que percebia o mundo acrescentando algo à matéria. Não se trata mais de reconhecer ou de introduzir a lei, seja ela paterna como na psicanálise lacaniana, seja ela uma norma social como nos pressupostos de adequação do comportamentalismo, seja ela uma intencionalidade, como na fenomenologia. Para Sauvagnargues (2020) a criação é subtrativa, justamente, porque ela infirma a lei.

A hipótese com a qual estamos trabalhando é de que exista uma teoria da criação na obra da Anne Sauvagnargues. A qual estaria relacionada ao mesmo tempo, com o conceito de bloqueio que ela busca distinguir de resistência e com a noção de subtração enquanto invalidação da lei naturalizada, a qual nos impede - quase sempre - de perceber que a defesa de sistemas coerentes são imposições de uma determinada leitura. Um exemplo interessante é o da gramática. Quando dizemos que a exceção confirma a regra estamos tentando esconder o fato que as línguas são tecidos anacrônicos, com múltiplas regras. Trata-se de uma ação extremamente violenta onde se busca impor uma única regra como regência para toda língua. $\bigcirc$ mesmo se pode afirmar para os processos de subjetivação.

Não é somente ser um monstro, não é apenas não ter a generalidade, não preencher a generalidade, não preencher a generalidade da norma, mas é mostrar que nós somos todos deficientes. Não há relação com a lei que não seja sob o modo da deficiência, nós não temos relação com a lei senão através daquilo em que não correspondemos à lei. (SAUVAGNARGUES, 2020, p.10)

Compreender que somos, de certa forma, todos deficientes é abandonar a imagem romântica do gênio criador. $O$ ato de criação, antes pensado como 
ação individualizada de um sujeito especial, necessita agora de acoplamentos, agenciamentos, conexões. Não se trata mais de reconhecer a lei, ou de internalizá-la, mas sim de invalidar, infirmar a lei. Dizendo de modo bastante assertivo: o bloqueio é quem cria, não é o sujeito. Pois, o sujeito está sempre a reboque das máquinas desejantes. (DELEUZE; GUATTARI, 2010). Ou seja, é diante o bloqueio que criamos. A criação está relacionada, ao mesmo tempo, com um bloqueio e com uma linha de fuga. De modo geral, o que fazemos ao criar é traçar uma linha de fuga diante de um bloqueio.

Finalmente, temos condições de colocar, ainda que de modo bastante preliminar, algumas questões - envolvendo o conceito de bloqueio - sobre os processos de criação em Anne Sauvagnargues.

\section{Considerações}

Se as condições de criação se efetuam a partir de uma forma de bloqueio, se o bloqueio é quem cria, seria possível considerar que o atelier tradicional - onde assistimos o grande pintor - quase sempre branco, europeu, masculino - produzindo sua obra-prima isolado no silêncio de sua intimidade - apareceria bloqueado nos transportes públicos utilizados pela artista? As pinturas de Anne Sauvagnargues estariam se relacionando com tais bloqueios? A impossibilidade de trabalhar com o apoio de uma mesa estável ou de um cavalete, de utilizar telas, pincéis, paleta, tinta a óleo, tinta acrílica, aquarela, nanquim, enfim, de utilizar o próprio atelier como instrumento de trabalho, modificaria a relação do artista com a obra? Pensar a criação a partir destes atravessamentos, nos traria novas formas de perceber a pintura? Em que medida a linha de fuga traçada por Anne Sauvagnargues está relacionada com o bloqueio de uma zona tradicional de criação?

O conceito apresentado pela filósofa parece inserir novos elementos ao debate que envolve o ato de criação e sua relação com o espaço de criação. Contudo, talvez possamos melhorar essa leitura retomando às três pinturas citadas anteriormente. As obras "Station Saint Michel" (fig.1), "Viva Italia!" (fig.2), "Arrêt à Marseille" (fig.3) são agenciamentos com as cidades. Linhas que configuram fragmentos daquilo que atravessa o corpo da artista, enquanto se move pela França e pela Itália. É através da pintura que Anne encontra um espaço de experimentação que abriga indícios de seu contato com o mundo e as paisagens. Movimento que envolve o corpo e o pensamento. Desse modo, seu processo de criação é guiado por uma forma de pensar o campo pictórico como algo que inclui o próprio lugar da experiência de seu deslocamento, rompendo com o universo tradicional da pintura, elaborada dentro do ambiente reservado e interno do atelier. Trata-se de pensar a pintura para além de seus limites ou formas de suporte.

O que constitui o campo específico de uma obra de pintura é seu campo interno mas não os limites ou formas do seu suporte; o campo ampliado 
refere-se ao que o expande, mas de dentro de um pensamento pictórico; o fora-do-campo da pintura seria o que a projeta para além de seus próprios limites. (CATTANI, 2011, p.23)

Esta ampliação cria condições de possibilidade para que o nosso olhar sedentário, viciado pelo jogo tela-representação-parede seja lançado à violência das forças de composição. Nessa perspectiva, somos forçados a subtrair em busca de um sentido, em busca de uma imagem. Uma vez que a percepção torna-se subtração, surge a pergunta: quando olho para as cidades de Anne o que tais cidades veem em mim? Quando percebo uma rua, um prédio, uma estação de trem, o que tais elementos percebem no meu olhar? Trata-se de um movimento que nos leva para lá e para cá; zigue-zague. Ora percebemos uma imagem que em um curto espaço de tempo deixa de existir em nosso enquadramento, dando espaço para a configuração de outras cenas. Ora isso se inverte e temos a impressão de objetivar uma paisagem. São traços firmes que constituem fluxos, caminhos, percursos. Anne nos dá condições para que, assim como ela, possamos nos movimentar através de suas obras. Sim, trata-se de uma imagem movimento, mas também de uma imagem/tempo.

A percepção aberta pelas pinturas de Anne Sauvagnargues está relacionada com um movimento que seu próprio corpo sofre - espécie de geografia do processo de criação - e com uma virtualidade que precede a percepção. O bloqueio aparece aqui, ao lado do virtual. É ele que precede todo o processo. Pois, sem o bloqueio, não haveria linha de fuga. E sem a linha de fuga não haveria processo de criação. Cabe lembrar aqui, que uma linha de fuga, no sentido proposto pela filosofia da diferença, é sempre uma desterritorialização. Pois, para Deleuze e Guattari, o problema "está menos numa mudança de situação ou na abolição de qualquer situação do que na vacilação, no susto, na desorganização de uma situação qualquer" (ZOURABICHVILI, 2004, p.58).

Assim, se a linha de fuga desorganiza, é preciso lembrar que esta desorganização é precedida por algo. Isto que precede a linha de fuga é que estamos chamando de bloqueio. Da mesma forma, como só se pensa por que se é forçado, só se traça uma linha de fuga porque se é forçado. E quem nos força é o bloqueio. É dessa forma, que Sauvagnargues defende, como vimos ao longo do ensaio, que o processo de criação é disparado pelo bloqueio. Já que ele é primeiro. Nesse sentido, seria possível nos aproximarmos da questão deste ensaio da seguinte forma: a linha de fuga que Anne Sauvagnargues encontra, permite a ela um processo de criação em trânsito, no deslocamento do espaço que a bloqueia.

As pinturas de Anne Sauvagnargues nos ajudam a compreender que o ato de criação não é produzido pela imaginação privada do gênio artista, mas sim por uma complexa composição de linhas de forças que nos atravessam. Ou seja, os processos de criação não dependem exclusivamente do desejo pessoal, interno, individual do grande criador. Já que em boa medida o ato de criação é impessoal, pré-individual. São pinturas onde podemos ouvir o riso de Anne enunciando que não se trata de imaginar, representar o movimento, mas sim de agenciar-se com ele. Como Deleuze (2007) aponta em 'Francis Bacon - Lógica da Sensação' a imagem é real porque ela 
produz algo, ela produz sensações.

Do mesmo modo, pode-se afirmar que estas pinturas contestam as concepções metafísicas - onde boa parte da psicologia moderna encontra fundamentação pautadas quase sempre por um ato de criação isolado, o qual seria elaborado num espaço interno do grande artista. Para este espaço, sabemos, vários conceitos foram forjados por tais psicologias na tentativa de explicar os processos de criação: imaginação, imaginário, dom, aptidão, talento, gênio e se formos um pouco adiante: personalidade, self, consciência, identidade etc. Essa espécie de imagem criacionista, onde o ato de criação tem sempre origem num sujeito ativo, artista criador, que à semelhança do Deus judaico-cristão inventa mundos sem uma relação anterior com o mundo, é colocada em xeque. A obra de Anne Sauvagnargues nos ajuda a compreender que os processos de criação estão mais relacionados com o bloqueio e com a subtração do que propriamente com o desejo individual do artista.

\section{Referências}

ABECEDÁRIO de Gilles Deleuze. Direção: Pierre-André Boutang. Produção: Éditions Montparnasse. Entrevistadora: Claire Parnet. Paris, 1998. Disponível em: <http:// escolanomade.org/wp-content/downloads/deleuze-o-abecedario.pdf >Acessado em: 19 de jun. de 2020.

CATTANI, Icleia. Artistas: pintura pura. In: FARIAS, Agnaldo (org.) Icleia Cattani. Rio de Janeiro: Funarte, 2004. p. 87 -.98.

Poiética, matéria, campos nas pinturas de Karin Lambrecht. Revista Porto Arte, Porto Alegre, v.18, n.31, p.17-30, nov, 2011.

COSTA, Clóvis Martins. Provocações para fazer/pensar a pintura: notas de atelier. In: seminário Deleuze: modos de usar. Sobre Destruições e Invenções de Mundos. Palestra realizada em 12 de agosto de 2020. Disponível em: < https://www.facebook.com/101019808325084/ videos/3205407559544807 >. Acesso em 19 de agosto de 2020.

DELEUZE, Gilles. A ilha deserta. Edição preparada por David Lapujade. São Paulo: iluminuras, 2006.

Diferença e Repetição. Rio de Janeiro: Graal, 2006b.

Dois regimes de loucos: textos e entrevistas. Trad. Guilherme Ivo. São Paulo: Editora 34, 2016.

Francis Bacon: Lógica da sensação. Rio de Janeiro: Jorge Zahar Editor, 2007.

DELEUZE, Gilles; GUATTARI, Félix. Mil platôs: capitalismo e esquizofrenia. vol.3 Rio de Janeiro: Editora 34, 1996. 
O Anti-Édipo. Trad. Luiz B. L. Orlandi. São Paulo: Editora 34, 2010.

O que é a Filosofia? Trad. Bento Prado Jr.; Alberto Alonso Munhoz. São Paulo:

Editora 34, 2010.

NEUMANN, Eckhard. Mitos de artista, estudio psicohistórico sobre la creatividad. Madrid: Tecnos, 1992

SAUVAGNARgUES, Anne. Deleuze: Del animal al arte. Trad. Irene Agoff. Buenos Aires: Amorrortu editores, 2006.

Deleuze et l'art. Presses Universitaires de France, 2005.

Somos nada mais que imagens entrevista com Anne Sauvagnargues. [Entrevista concedida a] Édio Raniere. Rev. Polis e Psique, v.10, n.1, p. 6-29, 2020.

SOUZA, Leonara. Estética e história da arte contemporânea. Rio de Janeiro: Seses, 2016.

ZOURABICHVILI, François. O Vocabulário de Deleuze. Rio de Janeiro: Relume Dumará, 2004.

Recebido em 20 de julho de 2020.

Aprovado em 19 de agosto de 2020. 